\title{
Aktivitas fisik dengan penyakit jantung koroner di Indonesia
}

\author{
The relationships of physical activity with coronary heart disease in Indonesia \\ Diyan Yunanto Setyaji ${ }^{1}$, Yayi Suryo Prabandari², I Made Alit Gunawan ${ }^{3}$ \\ ${ }^{1}$ Program Studi Sarjana Gizi, Sekolah Tinggi Ilmu Kesehatan Panti Rapih \\ ${ }^{2}$ Departemen Ilmu Perilaku, Lingkungan dan Sosial Kedokteran, Fakultas Kedokteran Universitas Gadjah Mada \\ ${ }^{3}$ Jurusan Gizi Politeknik Kesehatan Kementerian Kesehatan Yogyakarta
}

\begin{abstract}
Background: Coronary heart disease (CHD) is responsible for a substantial amount of early deaths, reduced quality of life and significant costs to the health and social care system. More than 3/4 CHD cases can prevented by lifestyle changes and focus on earlier risk factors management. Physical activity become a reference for the most important of primary and secondary prevention. Objective: To determine the relationship between physical activity and coronary heart disease in Indonesia. Method: This study used a cross-sectional design. Coronary heart disease's history, physical activity, age, sex, economic status and consumption of fatty food were obtained from Basic Health Research (Riskesdas) 2013. Riskesdas 2013 used multistage cluster sampling. Subject in this study was 374,506 women and 347,823 men above 15 years old in Indonesia who answered the coronary heart disease questions which was selected purposively. Data was analyzed by using descriptive analysis, Chi-Square and multiple logistic regression. Results: Those who did not perform vigorous-intensity physical activity or who only did it less than 80 minutes per week had a higher prevalence of CHD than those who were more active [2,63 (2,44-2,86); $p=0,00]$. Conclusion: Physical activity had a significant association with CHD events in people above 15 years old in Indonesia.
\end{abstract}

KEY WORDS: coronary heart disease; physical activity; riskesdas

\begin{abstract}
ABSTRAK
Latar belakang: Penyakit jantung koroner (PJK) bertanggung jawab atas sejumlah besar kematian dini, penurunan kualitas hidup, dan tingginya biaya sistem kesehatan. Lebih dari 3/4 kasus PJK dapat dicegah dengan perubahan gaya hidup dan fokus terhadap faktor risiko sedari dini. Aktivitas fisik menjadi acuan sebagai upaya pencegahan primer dan sekunder yang bersifat nonfarmakologikal paling penting. Tujuan: Tujuan penelitian ini adalah mengetahui hubungan antara aktivitas fisik dengan penyakit jantung koroner di Indonesia. Metode: Desain penelitian ini adalah cross-sectional. Riwayat penyakit jantung koroner, aktivitas fisik, usia, jenis kelamin, status ekonomi, dan konsumsi pangan berlemak diperoleh dari Riset Kesehatan Dasar (Riskesdas) 2013. Teknik pengambilan sampel pada Riskesdas 2013 adalah multistage cluster sampling. Penelitian ini melibatkan 374.506 wanita dan 347.823 pria berusia di atas 15 tahun yang menjawab pertanyaan terkait PJK. Data dianalisis dengan menggunakan analisis deskriptif, Chi-Square, dan regresi logistik berganda. Hasil: Pada mereka yang tidak melakukan aktivitas berat atau yang hanya melakukan kurang dari 80 menit setiap minggunya ditemukan prevalensi PJK yang lebih tinggi dibandingkan dengan mereka yang jauh lebih aktif $[2,63(2,44-2,86) ; \mathrm{p}=0,00]$. Simpulan: Aktivitas fisik memiliki hubungan yang signifikan dengan kejadian penyakit jantung koroner pada orang di atas usia 15 tahun di Indonesia.
\end{abstract}

KATA KUNCI: penyakit jantung koroner; aktivitas fisik; riskesdas

\section{PENDAHULUAN}

Penyakit jantung koroner (PJK) adalah istilah untuk penyakit yang muncul ketika dinding arteri koronaria menyempit oleh pembentukan material lemak secara gradual. Penyakit ini tidak memiliki gejala pada awal pembentukannya dan merupakan gangguan kronis yang berkembang diam-diam di sepanjang hidup (1-3). Penyakit jantung koroner bertanggungjawab atas sejumlah besar kematian dini, penurunan kualitas hidup, dan tingginya biaya sistem kesehatan dan

Korespondensi: Diyan Yunanto Setyaji, Program Studi Sarjana Gizi, Sekolah Tinggi Ilmu Kesehatan Panti Rapih Yogyakarta, Jl. Tantular 401 Pringwulung, Condongcatur, Depok, Sleman, Yogyakarta, e-mail: diyansetyaji@gmail.com 
perawatan sosial. World Health Organization (WHO) mengestimasikan PJK menjadi penyebab utama kematian di seluruh dunia dengan 17 juta kematian per tahun pada tahun 2008 dan akan meningkat menjadi 23,4 juta kematian pada tahun 2030 , dengan lebih dari $80 \%$ terjadi di negara berkembang (3). Menurut data Riskesdas 2013 menunjukkan prevalensi PJK di Indonesia berdasarkan wawancara terdiagnosis dokter sebesar $0,5 \%$ dan berdasarkan terdiagnosis dokter atau gejala sebesar $1,5 \%$ (4). Penyakit jantung koroner juga menyebabkan disabilitas massal, yang pada dekade berikutnya angka disability-adjusted life years (DALYs) meningkat dari 85 juta DALYs pada 1990 menjadi sekitar 150 juta DALYs pada 2020. Hal ini mengakibatkan hilangannya produktivitas secara global (5). Biaya yang dikeluarkan terkait dengan kematian dini akibat PJK, produktivitas yang rendah, penanganan di rumah sakit, dan resep obat juga sangat tinggi. Kerugian yang harus ditanggung dalam 1 tahun mencapai 19 triliun poundsterling untuk wilayah Inggris, 196 triliun euro untuk wilayah ekonomi Uni Eropa, dan 327 milyar US dollar untuk wilayah Amerika Serikat (6).

Interheart, sebuah studi kasus kontrol di 52 negara menemukan bahwa 90\% kasus PJK dapat dikaitkan dengan faktor risiko yang sebenarnya dapat dicegah dan diperbaiki (7). Beberapa faktor risiko saling berhubungan dan terdapat bukti jelas bahwa eliminasi faktor risiko akan mengurangi proporsi kejadian PJK secara signifikan. Lebih dari 3/4 kasus PJK dapat dicegah dengan perubahan gaya hidup dan fokus terhadap faktor risiko sejak dini $(3,8)$. Gaya hidup sedenter menjadi salah satu faktor risiko PJK $(9,10)$ sedangkan aktivitas fisik reguler berhubungan dengan penurunan risiko pada individu yang sehat (11), individu dengan faktor risiko (12), bahkan pasien dengan penyakit jantung $(13,14)$ dalam cakupan usia yang luas.

Penelitian ini bertujuan untuk menganalisis hubungan antara PJK dan aktivitas fisik di Indonesia dengan menggunakan data Riskesdas tahun 2013. Bagi instansi pemerintah, penelitian ini dapat digunakan sebagai bahan pertimbangan dalam perencanaan program pencegahan dan penanggulangan masalah PJK di Indonesia. Penelitian ini juga dapat digunakan sebagai sumber informasi untuk masyarakat tentang faktor-faktor risiko PJK sehingga kejadian jantung koroner dapat dicegah dan ditangani.

\section{BAHAN DAN METODE}

Penelitian ini menggunakan desain cross sectional dengan menggunakan data sekunder dari Riskesdas 2013 yang diambil pada tanggal 1 Mei hingga 30 Juni 2013 di 33 provinsi, 497 kabupaten/kota di Indonesia. Permintaan data diawali dengan mengirimkan proposal beserta surat permohonan penggunaan data kepada Kepala Badan Penelitian dan Pengembangan Kesehatan (Litbangkes) Indonesia. Izin penelitian dan kelaikan etik diperoleh dari Komite Etik Penelitian Kesehatan dan Kedokteran (MHREC) Universitas Gadjah Mada dengan nomor surat KE/FK/119/EC/2016. Populasi pada penelitian ini adalah semua rumah tangga yang memiliki anggota keluarga berusia di atas 15 tahun dengan sampel semua orang di atas 15 tahun di Indonesia yang berjumlah 722.329 orang yang terdiri dari 374.506 wanita dan 347.823 pria. Kriteria inklusi subjek penelitian ini adalah semua orang di atas 15 tahun yang menjadi sampel Riskesdas 2013 sedangkan kriteria eksklusinya adalah sampel data yang tidak lengkap pada variabel-variabel terkait (aktivitas fisik, usia, jenis kelamin, status ekonomi, konsumsi pangan berlemak).

Subjek diklasifikasikan memiliki riwayat PJK (angina pektoris dan/atau infark miokard) jika pernah didiagnosis oleh dokter atau belum pernah didiagnosis oleh dokter tetapi pernah mengalami gejala nyeri di dalam dada/rasa tertekan berat atau tidak nyaman di dalam dada; nyeri/tidak nyaman di dada dirasakan di dada bagian tengah/dada kiri/menjalar ke lengan kiri; nyeri/ tidak nyaman dirasakan ketika mendaki/naik tangga/ berjalan tergesa gesa; dan nyeri/tidak nyaman di dada hilang ketika menghentikan aktivitas/istirahat. Subjek dikategorikan memiliki aktivitas fisik yang cukup jika melakukan aktivitas fisik berintensitas tinggi selama lebih dari 80 menit per minggu atau kombinasi aktivitas fisik berintensitas sedang dan tinggi. Total volume mingguan dari aktivitas fisik dan latihan aerobik didapatkan dengan penjumlahan beberapa kali aktivitas dalam seminggu yang berlangsung masing masing lebih dari atau sama dengan 10 menit, dengan aktivitas fisik tersebut terdistribusi di setiap hari dalam seminggu. 
Status ekonomi rumah tangga yang diukur berdasarkan atas indeks kepemilikan. Subjek dikategorikan berstatus ekonomi rendah jika berada dalam kuintil 1, 2, dan 3 serta dikategorikan tinggi jika berada dalam kuintil 4 dan 5. Perilaku konsumsi makanan berlemak atau digoreng diketahui dengan menghitung frekuensi asupan setiap harinya, minggu, dan bulan. Bahan makanan yang mengandung banyak lemak yaitu seperti daging berlemak, sop buntut, gorengan, makanan bersantan, makanan dengan banyak margarin, dan makanan berkolesterol seperti jerohan, telur, udang. Subjek dikategorikan jarang mengkonsumsi pangan berlemak jika tidak setiap hari mengkonsumsi makanan jenis ini, tetapi hanya 3-6 kali per minggu, 1-2 kali seminggu, atau kurang dari 3 kali per bulan. Sementara itu, subjek dikategorikan sering jika subjek mengkonsumsi makanan jenis ini satu kali atau lebih setiap hari. Analisis univariat dilakukan untuk mengetahui karakteristik dan distribusi data. Analisis bivariat untuk menguji hubungan antara variabel bebas dan variabel terikat dengan uji Chi-Square. Analisis multivariat dilakukan dengan menggunakan uji regresi logistik.

\section{HASIL}

Proporsi subjek penelitian ini tersebar hampir merata pada kedua jenis kelamin. Sebagian besar subjek berusia dewasa dan berstatus ekonomi rendah. Tabel 1 menunjukkan bahwa dari total subjek penelitian, sebanyak 0,56\% didiagnosis menderita PJK. Berdasarkan Tabel 1 juga diketahui bahwa mayoritas penderita PJK adalah kelompok usia lansia, berjenis kelamin wanita, berstatus ekonomi rendah, dan memiliki kebiasaan jarang mengkonsumsi pangan berlemak. Hasil analisis bivariat menunjukan bahwa subjek yang berusia di atas 65 tahun memiliki prevalensi PJK hampir 33 kali lebih besar dibandingkan dengan remaja dengan rentang usia 15-25 tahun (95\% CI: 26,81-41,30). Prevalensi PJK pada wanita 1,2 kali lebih tinggi dibandingkan dengan pria (95\% CI: 1,13-1,28). Subjek yang tinggal dalam keluarga dengan status ekonomi terendah memiliki prevalensi PJK sebesar 3,32 kali lebih tinggi dibandingkan dengan yang tinggal dalam keluarga berstatus ekonomi tertinggi ( $95 \% \mathrm{CI}$ : 2,96-3,76; $\mathrm{p}=0,00$ ). Konsumsi makanan berlemak tidak menunjukkan hubungan yang bermakna secara statistik dengan prevalensi PJK di Indonesia [0,99 (95\% CI: 0,92-1,05); $\mathrm{p}=0,76]$.

Tabel 1. Hubungan antara usia, jenis kelamin, status ekonomi, dan konsumsi pangan berlemak dengan kejadian penyakit jantung koroner

\begin{tabular}{|c|c|c|c|c|c|c|c|}
\hline \multirow{3}{*}{ Variabel } & \multicolumn{4}{|c|}{ PJK } & \multirow{3}{*}{ PR } & \multirow{3}{*}{$\mathbf{p}$} & \multirow{3}{*}{$95 \%$ CI } \\
\hline & \multicolumn{2}{|c|}{ Ya } & \multicolumn{2}{|c|}{ Tidak } & & & \\
\hline & $\mathbf{n}$ & $\%$ & n & $\%$ & & & \\
\hline \multicolumn{8}{|l|}{ Usia (tahun) } \\
\hline Manula $(\geq 66)$ & 939 & 23,08 & 50.666 & 7,05 & 32,69 & $0,00^{*}$ & $26,81-41,30$ \\
\hline Lansia (46-65) & 2.183 & 53,67 & 201.018 & 27,98 & 19,30 & $0,00^{*}$ & $15,79-24,06$ \\
\hline Dewasa (26-45) & 855 & 21,02 & 304.971 & 42,45 & 5,02 & $0,00 *$ & $4,05-6,25$ \\
\hline Remaja (15-25) & 90 & 2,21 & 161.607 & 22,49 & & & \\
\hline \multicolumn{8}{|l|}{ Jenis kelamin } \\
\hline Wanita & 2.297 & 56,47 & 372.209 & 51,82 & \multirow{2}{*}{1,20} & \multirow{2}{*}{$0,00^{*}$} & \multirow{2}{*}{$1,13-1,28$} \\
\hline Pria & 1.770 & 43,52 & 346.053 & 48,17 & & & \\
\hline \multicolumn{8}{|l|}{ Status ekonomi } \\
\hline Terbawah & 1.314 & 32,30 & 150.449 & 20,94 & 3,32 & $0,00^{*}$ & $2,96-3,76$ \\
\hline Menengah bawah & 1.004 & 24,68 & 150.388 & 20,93 & 2,54 & $0,00 *$ & $2,26-2,88$ \\
\hline Menengah & 823 & 20,23 & 145.951 & 20,32 & 2,15 & $0,00^{*}$ & $1,90-2,44$ \\
\hline Menengah atas & 580 & 14,26 & 139.073 & 19,36 & 1,59 & $0,00 *$ & $1,39-1,82$ \\
\hline Teratas & 346 & 8,50 & 132.401 & 18,43 & & & \\
\hline \multicolumn{8}{|c|}{ Konsumsi pangan berlemak } \\
\hline Sering ( $\geq 1$ kali/hari) & 1.344 & 33,04 & 238.922 & 33,26 & \multirow{2}{*}{0,99} & \multirow{2}{*}{0,76} & \multirow{2}{*}{$0,92-1,05$} \\
\hline Jarang & 2.723 & 66,95 & 479.340 & 66,73 & & & \\
\hline
\end{tabular}

$\mathrm{PJK}=$ penyakit jantung koroner; $\mathrm{PR}=$ rasio prevalensi; *bermakna $(\mathrm{p}<0,05)$ 
Tabel 2. Hubungan antara aktivitas fisik berat dengan kejadian penyakit jantung koroner

\begin{tabular}{|c|c|c|c|c|c|c|c|}
\hline \multirow{3}{*}{ Variabel } & \multicolumn{4}{|c|}{ PJK } & \multirow{3}{*}{ PR } & \multirow{3}{*}{$\mathbf{p}$} & \multirow{3}{*}{$95 \%$ CI } \\
\hline & \multicolumn{2}{|c|}{ Ya } & \multicolumn{2}{|c|}{ Tidak } & & & \\
\hline & $\mathbf{n}$ & $\%$ & $\mathbf{n}$ & $\%$ & & & \\
\hline \multicolumn{8}{|l|}{ Aktivitas fisik berat } \\
\hline Kurang & 3.328 & 81,82 & 452.370 & 62,98 & \multirow{2}{*}{2,63} & \multirow{2}{*}{$0,00^{*}$} & \multirow{2}{*}{$2,44-2,86$} \\
\hline Aktif ( $\geq 80$ menit/mgg) & 739 & 18,17 & 265.892 & 37,01 & & & \\
\hline
\end{tabular}

*bermakna $(\mathrm{p}<0,05)$

Tabel 3. Model regresi logistik hubungan antara aktivitas fisik dengan penyakit jantung koroner

\begin{tabular}{|c|c|c|c|c|}
\hline Variabel & Model 1 & Model 2 & Model 3 & Model 4 \\
\hline \multicolumn{5}{|l|}{ Aktivitas berat } \\
\hline Aktif berat & 1 & 1 & 1 & 1 \\
\hline Kurang aktif & $\begin{array}{c}2,69 * \\
(2,48-2,92)\end{array}$ & $\begin{array}{c}2,68 * \\
(2,47-2,91)\end{array}$ & $\begin{array}{c}2,29 * \\
(1,29-1,68)\end{array}$ & $\begin{array}{c}2,26^{*} \\
(2,07-2,46)\end{array}$ \\
\hline \multicolumn{5}{|l|}{ Usia } \\
\hline Remaja & 1 & & & 1 \\
\hline Dewasa & $\begin{array}{c}5,76^{*} \\
(4,63-7,16)\end{array}$ & & & $\begin{array}{c}5,58^{*} \\
(4,48-6,93)\end{array}$ \\
\hline Lansia & $\begin{array}{c}22,21^{*} \\
(17,98-27,43)\end{array}$ & & & $\begin{array}{c}21,71^{*} \\
(17,58-26,82)\end{array}$ \\
\hline Manula & $\begin{array}{c}32,17^{*} \\
(25,90-39,95)\end{array}$ & & & $\begin{array}{c}36,15^{*} \\
(29,10-44,90)\end{array}$ \\
\hline \multicolumn{5}{|l|}{ Jenis kelamin } \\
\hline Pria & & 1 & & 1 \\
\hline Wanita & & $\begin{array}{c}0,95 \\
(0,89-1,01)\end{array}$ & & $\begin{array}{c}1,00 \\
(0,94-1,07)\end{array}$ \\
\hline \multicolumn{5}{|l|}{ Status ekonomi } \\
\hline Teratas & & & 1 & 1 \\
\hline Menengah atas & & & $\begin{array}{c}1,47^{*} \\
(1,29-1,68)\end{array}$ & $\begin{array}{c}1,47^{*} \\
(1,28-1,68)\end{array}$ \\
\hline Menengah & & & $\begin{array}{c}1,88^{*} \\
(1,66-2,14)\end{array}$ & $\begin{array}{c}2,00^{*} \\
(1,76-2,27)\end{array}$ \\
\hline Menengah bawah & & & $\begin{array}{c}2,12^{*} \\
(1,87-2,40)\end{array}$ & $\begin{array}{c}2,43^{*} \\
(2,15-2,75)\end{array}$ \\
\hline Terbawah & & & $\begin{array}{c}2,66^{*} \\
(2,36-3,00)\end{array}$ & $\begin{array}{c}3,07^{*} \\
(2,72-3,47)\end{array}$ \\
\hline $\mathrm{n}$ & 722.329 & 722.329 & 722.329 & 722.329 \\
\hline Log likelihood & $23.058,26$ & $24.776,108$ & $24.601,812$ & $22.816,243$ \\
\hline Pseudo $\mathrm{R}^{2}$ & 0,0821 & 0,0137 & 0,0207 & 0,0917 \\
\hline
\end{tabular}

Berdasarkan data pada Tabel 2 diketahui bahwa hanya $36,91 \%$ subjek yang termasuk dalam kategori aktif melakukan aktivitas fisik berat minimal 80 menit per minggu. Mayoritas dari penderita PJK juga tergolong kurang aktif secara fisik. Pada subjek yang tidak melakukan aktivitas berat atau yang hanya melakukan aktivitas berat kurang dari 80 menit di setiap minggunya, ditemukan prevalensi PJK yang lebih tinggi dibandingkan dengan subjek yang jauh lebih aktif [2,63 (95\% CI: 2,44-2,86); $\mathrm{p}=0,00]$.

Analisis multivariabel (Tabel 3) yang dilakukan dengan uji regresi logistik menghasilkan beberapa model regresi dalam menganalisis hubungan antara kejadian PJK dan faktor-faktor yang mempengaruhinya. Model yang dianggap paling baik dalam memprediksi kejadian 
PJK adalah Model 1 karena bersifat parsimonious. Model ini menyebutkan bahwa rasio prevalensi PJK yang lebih tinggi pada orang dewasa, baik pria maupun wanita jika mereka memiliki aktivitas fisik berat yang rendah. Hal ini berarti kurangnya aktivitas fisik dapat meningkatkan prevalensi PJK pada kelompok usia dewasa dan lansia. Dibandingkan dengan model lainnya, model ini cukup baik untuk menjelaskan faktor-faktor penting yang berhubungan dengan kejadian PJK dengan mempertimbangkan nilai $\mathrm{R}^{2}$, rasio prevalensi yang relatif terjaga di antara semua model yang ada, serta terdapat bukti teoritis yang dapat dijelaskan secara ilmiah. Semua variabel yang terdapat dalam model terpilih memiliki hubungan yang signifikan dengan kejadian PJK di Indonesia.

\section{BAHASAN}

Penyakit jantung koroner disebabkan oleh penyempitan dinding arteri koronaria karena pembentukan lemak yang berakibat pada penurunan aliran darah di dalam pembuluh darah. Hal ini akan mengakibatkan penurunan pemenuhan kebutuhan oksigen otot jantung sehingga menyebabkan penurunan fungsi otot jantung dan kerusakan sel otot jantung (2). Penyakit ini dapat menyerang kelompok usia produktif sehingga banyak keluarga yang terpaksa harus kehilangan sumber pendapatan dan terbebani biaya pengobatan dan perawatan yang besar dan pada akhirnya beban perekonomian negara juga akan terus meningkat (5).

Hasil analisis bivariat menunjukan bahwa aktivitas fisik memiliki hubungan yang signifikan dengan kejadian PJK di Indonesia $(p=0,00)$. Prevalensi PJK lebih banyak ditemukan pada kelompok orang yang tidak melakukan aktivitas fisik berat atau melakukan aktivitas fisik berat tetapi kurang dari 80 menit di setiap minggunya dibandingkan dengan mereka yang jauh lebih aktif. Mayoritas penderita penyakit ini juga merupakan kelompok orang yang kurang aktif secara fisik. Efek proteksi dari aktivitas fisik terhadap terjadinya PJK sesuai dengan hasil penelitian sebelumnya di Amerika bahwa terdapat penurunan risiko PJK dengan melakukan aktivitas fisik berat selama 30 menit dalam beberapa hari di setiap minggunya (15). Hasil tersebut didukung oleh penelitian yang menyebutkan bahwa aktivitas fisik yang rendah dan peningkatan aktivitas sedenter menjadi faktor prediksi utama dalam kematian dini akibat PJK (16).

Aktivitas fisik dapat menurunkan konsentrasi plasma fibrinogen. Semakin rendah konsentrasi plasma fibrinogen, semakin rendah pula risiko pembentukan trombus yang diikuti dengan peningkatan aktivator plasminogen jaringan (t-PA) dan penurunan plasminogen activator inhibitor-1 (PAI-1), serta penurunan adhesi atau agregasi platelet yang akan berdampak pada penurunan risiko kemungkinan terjadinya PJK. Jika dibandingkan dengan orang yang menjalani keseharian dengan aktivitas sedenter, mereka yang memiliki aktivitas fisik secara regular memiliki profil fibrinolitik yang lebih efektif dan penurunan risiko pembentukan trombus. Pada pemilik gaya hidup sedenter, kapasitas fibrinolitik menurun ketika konsentrasi plasma plasminogen aktivator inhibitor-1 (PAI-1) meningkat sehingga memicu koagulasi darah yang lebih luas $(5,15)$. Lebih lanjut, perfusi miokardium dapat ditingkatkan dengan aktivitas fisik secara teratur karena terjadi peningkatan diameter interior dari arteri koroner, augmentasi mikrosirkulasi, dan peningkatan fungsi endotelial (17). Efek lain dari aktivitas reguler ini adalah efek antitrombotik yang dapat menurunkan risiko oklusi koroner akibat dari plak seperti peningkatan volume plasma, penurunan viskositas darah, penurunan agregasi platelet, dan peningkatan kemampuan trombolitik (18).

Studi klinis menunjukkan bahwa aktivitas fisik dapat menurunkan risiko PJK melalui mekanisme mencegah atau menunda perkembangan hipertensi pada subjek normotensi dan penurunan tekanan darah pada pasien dengan hipertensi, meningkatkan level kolesterol highdensity lipoprotein (HDL) dan kontrol adiposit, membantu mengontrol berat badan, menurunkan risiko perkembangan diabetes mellitus tipe 2 dengan meningkatkan toleransi glukosa dan sensitivitas insulin, serta berkontribusi pada kekuatan otot dan mobilitas yang menunjang kualitas hidup $(9,15,16)$. Aktivitas fisik selama 30 menit yang dilakukan secara rutin 3-5 hari dalam seminggu dapat menurunkan jumlah kolesterol low-density lipoprotein (LDL) hingga $10 \mathrm{mg} / \mathrm{dL}$ dan meningkatkan kolesterol HDL hingga 4 $\mathrm{mg} / \mathrm{dL}$. Penurunan signifikan profil kolesterol secara keseluruhan dan LDL yang diikuti peningkatan kolesterol HDL diketahui memiliki pengaruh positif pada kesehatan kardiovaskuler (15). 
Hasil analisis bivariat menunjukan bahwa usia berhubungan signifikan dengan kejadian PJK di Indonesia $(p=0,00)$. Mayoritas penderita PJK termasuk ke dalam kelompok usia lansia. Namun, jika dibandingkan dengan kelompok usia remaja, prevalensi PJK paling tinggi ditemukan pada kelompok usia manula. Banyak penelitian epidemiologis prospektif menyebutkan bahwa terdapat kaitan erat antara perkembangan aterosklerosis seiring dengan bertambahnya usia (1). Penelitian lain menunjukkan hasil serupa bahwa secara relatif, orang berusia muda memiliki risiko absolut PJK yang lebih rendah dalam rentang usia 10 tahun meskipun memiliki banyak faktor risiko lain (5).

Hubungan antara bertambahnya usia dan timbulnya PJK konsisten dengan yang telah diketahui sebelumnya tentang etiologi lesi aterosklerosis dan periode laten antara munculnya lesi lipid dan perkembangan plak (1). Bertambahnya usia juga mencerminkan lama paparan yang lebih panjang terhadap faktor-faktor aterogenik. Kerentanan terhadap aterosklerotik koroner dan paparan berbagai faktor risiko meningkat seiring peningkatan usia, seperti rasio HDL dan total kolesterol, tekanan darah sistolik, diabetes mellitus, dan aktivitas fisik. Organ jantung ketika usia tua cenderung tidak bekerja dengan baik. Dinding-dinding jantung akan menebal dan arteri dapat menjadi kaku dan mengeras, membuat jantung kurang mampu memompa darah ke otot-otot tubuh (5). Akibat perubahan fisik ini, prevalensi penyakit kardiovaskular lebih tinggi muncul pada kelompok usia lanjut.

Analisis bivariat juga menunjukan bahwa jenis kelamin berhubungan signifikan dengan kejadian PJK di Indonesia $(p=0,00)$. Prevalensi PJK lebih tinggi dijumpai pada kelompok wanita dibandingkan dengan pria. Mayoritas penderita PJK di Indonesia adalah kelompok wanita. Hasil ini sesuai dengan pernyataan yang menyebutkan bahwa di bawah usia 75 tahun, 42\% wanita meninggal dengan PJK sebagai penyebab utama dibandingkan dengan $38 \%$ pada pria (5). Perbedaan perilaku dan fisiologis antara pria dan wanita seperti lama paparan terhadap rokok, dislipidemia, dan perbedaan hormonal menjelaskan perbedan terkait dengan jenis kelamin (19). Sebelum usia menopause, rendahnya kejadian PJK pada wanita dijelaskan oleh efek proteksi estrogen endogen. Namun, setelah usia 65 tahun, risiko penyakit jantung hampir sama pada wanita dan pria ketika memiliki faktor-faktor risiko lain yang serupa $(5,19)$.

Lebih lanjut, hasil analisis bivariat menunjukan bahwa sosial ekonomi memiliki hubungan yang signifikan dengan kejadian PJK di Indonesia $(\mathrm{p}=0,00)$. Subjek yang tinggal dalam keluarga dengan status ekonomi terendah memiliki prevalensi PJK yang lebih tinggi dibandingkan dengan mereka yang tinggal dalam keluarga berstatus ekonomi tertinggi. Mayoritas penderita PJK di Indonesia berasal dari keluarga berstatus ekonomi rendah. Hal ini sejalan dengan hasil penelitian sebelumnya yang menyatakan bahwa orang dengan status ekonomi rendah mengalami peningkatan pada semua penyebab kematian akibat PJK (5). Status ekonomi rendah dikaitkan dengan rendahnya tingkat pendidikan yang dapat dicapai, rendahnya pendapatan, kepemilikan status pekerjaan yang rendah, dan tinggal dalam wilayah yang miskin. Penelitian di Australia menemukan adanya hubungan antara hadirnya sejumlah faktor risiko PJK dengan rendahnya status ekonomi rumah tangga (3). Faktor sosial ekonomi berkaitan dengan kebiasaan hidup yang kurang sehat dan kepatuhan dalam menaati anjuran kesehatan serta berdampak negatif pada orang setelah menderita infark miokardium (5).

Sementara hasil analisis multivariat (Tabel 3 Model 1) menunjukkan bahwa aktivitas fisik dan usia merupakan faktor yang paling menentukan prevalensi kejadian PJK pada orang di atas usia 15 tahun di Indonesia. Aktivitas fisik berhubungan dengan penurunan risiko kejadian PJK yang bersifat fatal maupun nonfatal pada individu yang sehat (12), individu dengan faktor risiko (13), dan pasien penyakit jantung (14) dalam cakupan usia yang luas. Secara relatif, orang berusia muda memiliki risiko absolut PJK yang lebih rendah dalam rentang usia 10 tahun meskipun memiliki banyak faktor risiko lain (5).

\section{SIMPULAN DAN SARAN}

Aktivitas fisik berhubungan signifikan dengan kejadian penyakit jantung koroner pada orang di atas usia 15 tahun di Indonesia. Perlu penelitian lebih lanjut dengan desain randomized controlled trials untuk mengetahui lebih jelas mengenai mekanisme kausalitas antara aktivitas fisik dengan kejadian penyakit jantung 
koroner di Indonesia. Selain itu, diperlukan analisis lebih lanjut mengenai aktivitas fisik moderat dan gaya hidup sedenter.

\section{UCAPAN TERIMA KASIH}

Ucapan terima kasih kami sampaikan kepada Badan Litbangkes Kementerian Kesehatan RI atas bantuan dan kerjasama yang baik dalam penyediaan data penelitian.

\section{Pernyataan konflik kepentingan}

Penulis menyatakan tidak ada konflik kepentingan dengan pihak-pihak yang terkait dalam penelitian ini.

\section{RUJUKAN}

1. Lichtenstein AH. Atherosclerosis. Dalam: Caballero B, ed. Encyclopedia of food sciences and nutrition. New York: Academic Press; 2003.

2. Kelley K, Kemple A, Rush C, Sarliker SE. Coronary heart disease. Washington: Washington State Department of Health; 2013.

3. O'Brien K. Living dangerously: Australians with multiple risk factors for cardiovascular disease. Canberra: Australian Institute of Health and Welfare; 2005.

4. Kementerian Kesehatan RI. Badan Penelitian dan Pengembangan Kesehatan. Riset Kesehatan Dasar 2013. Jakarta: Kementerian Kesehatan RI; 2013.

5. Perk J, De Backer G, Gohlke H, Graham I, Reiner Z, Zannad F, et al. European Guidelines on cardiovascular disease prevention in clinical practice (version 2012). The fifth joint task force of the European Society of Cardiology and other societies on cardiovascular disease prevention in clinical practice (constituted by representatives of nine societies and by invited experts). Eur Heart J 2012;33(13):1635-701.

6. Krummel DA. Medical nutrition therapy in cardiovaskuler disease. Dalam: Mahan LK, Escott-stump S. Krause's food, nutrition, and diet therapy. 12th edition. Philadelphia: WB Saunders Company; 2008.

7. Yusuf S, Hawken S, Ounpuu S, Dans T, Avezum A, Lanas F, et al. Effect of potentially modifiable risk factors associated with myocardial infarction in 52 countries (the INTERHEART study): case-control study. Lancet 2004;364:937-52

8. Mann J. Penyakit kardiovaskuler. Dalam: Gibney MJ, Margetts BM, Kearney JM, ed. Gizi kesehatan masyarakat. Andry Hartono (Alih bahasa). Jakarta: EGC; 2009.

9. Huffman FG, Nath S. Coronary heart disease: prevention. Dalam: Caballero B, ed. Encyclopedia of food sciences and nutrition. New York: Academic Press; 2003.

10. Warren TY, Barry V, Hooker SP, Sui X, Church TS, Blair SN. Sedentary behaviors increase risk of cardiovascular disease mortality in men. Med Sci Sports Exerc 2010;42(5):879-85.

11. Nocon M, Hiemann T, Müller-Riemenschneider F, Thalau F, Roll S, Willich SN. Association of physical activity with all-cause and cardiovascular mortality: a systematic review and meta-analysis. Eur J Cardiovasc Prev Rehabil 2008;15(3):239-46.

12. Richardson CR, Kriska AM, Lantz PM, Hayward RA. Physical activity and mortality across cardiovascular disease risk groups. Med Sci Sports Exerc 2004;36(11):1923-9.

13. Schnohr P, Scharling H, Jensen JS. Intensity versus duration of walking, impact on mortality: the Copenhagen City Heart Study. Eur J Cardiovasc Prev Rehabil 2007;14:72-8.

14. Taylor RS, Brown A, Ebrahim S, Jolliffe J, Noorani $\mathrm{H}$, Oldridge N, et al. Exercise-based rehabilitation for patients with coronary heart disease: systematic review and meta-analysis of randomized controlled trials. Am J Med 2004;116(10):682-92.

15. Sesso HD, Paffenbarger RS Jr, Lee IM. Physical activity and coronary heart disease in men: The Harvard Alumni Health Study. Circulation 2000;102(9):975-80.

16. Nicklett EJ, Semba RD, Xue QL, Tian J, Sun K, Fried LP, et al. Fruit and vegetable intake, physical activity, and mortality in older community-dwelling women. J Am Geriatr Soc 2012;60(5):862-68.

17. Di Francescomarino S, Sciartilli A, Di Valerio V, Di Baldassarre A, Gallina S. The effect of physical exercise on endothelial function. Sports Med 2009;39(10):797-812.

18. Lippi G, Maffulli N. Biological influence of physical exercise on hemostasis. Semin Thromb Hemost 2009;35:269-76.

19. Huffman FG, Koutoubi S, Nath S. Coronary heart disease: etiology and risk factor. Dalam: Caballero B, ed. Encyclopedia of food sciences and nutrition. New York: Academic Press; 2003. 